\title{
EDUCAÇÃO DE JOVENS E ADULTOS E EDUCAÇÃO ESPECIAL NO CONTEXTO DA EDUCAÇÃO INCLUSIVA: CONFLUÊNCIAS
}

\section{ARTIGO ORIGINAL}

LOPES, Giovana Cerqueira ${ }^{1}$, LINO, Lucília Augusta ${ }^{2}$

LOPES, Giovana Cerqueira. LINO, Lucília Augusta. Educação de jovens e adultos e educação especial no contexto da educação inclusiva: confluências. Revista Científica Multidisciplinar Núcleo do Conhecimento. Ano 06, Ed. 05, Vol. 03, pp. 4672. Maio de 2021. ISSN: 2448-0959, Link de acesso: https://www.nucleodoconhecimento.com.br/educacao/inclusiva-confluencias

\section{RESUMO}

Este artigo traz reflexões sobre a Educação de Jovens e Adultos na perspectiva inclusiva, além de apontar algumas dificuldades que os professores enfrentam nessas circunstâncias e sinalizar algumas possíveis soluções para tornar a inclusão mais eficaz. O trabalho tem como objetivo analisar o que dizem os estudos sobre a relação dos professores com a inclusão educacional de jovens e adultos com deficiências. Este estudo chama a atenção para a emergência do debate sobre a educação inclusiva na EJA, a partir de uma breve revisão da literatura e análise da legislação vigente. $O$ texto pretende, com base em estudos publicados: i - ampliar a reflexão sobre a inserção dos estudantes jovens e adultos, público-alvo da educação especial, na EJA, no contexto histórico e político-educacional; ii - identificar as principais

\footnotetext{
1 Pós-graduanda (EAD) em Planejamento, Gestão e Implementação da EAD, com Ênfase na Produção de Material Didático no Instituto Venturo; Concluindo a graduação no curso de Pedagogia da Universidade do Estado do Rio de Janeiro - UERJ. ${ }^{2}$ Orientadora.
}

RC: 84481

Disponível em: https://www.nucleodoconhecimento.com.br/educacao/inclusiva-confluencias 
dificuldades dos professores no cotidiano processo de inclusão; iii - apresentar possíveis estratégias para efetivar a inclusão. Percebemos que ainda há muito que discutir, pensar e pesquisar sobre a temática visando tornar a inclusão uma realidade nas turmas de EJA. No momento atual, a luta pela ampliação do direito à educação $e$ a resistência contra os ataques, desmontes e retrocessos para que a perda de direitos das pessoas com deficiência não continue crescendo, aumentando a exclusão.

Palavras-chave: Educação de Jovens e Adultos, Educação Especial, Educação Inclusiva.

\section{INTRODUÇÃO}

Com este artigo pretende-se discutir a relação da Educação de Jovens e Adultos (EJA) com a Educação Especial (EE) em uma perspectiva inclusiva, e, por conseguinte as dificuldades dos professores que atuam na modalidade EJA com alunos público-alvo da Educação especial.

A escolha desse tema surgiu ao deparar com as dificuldades encontradas por jovens e adultos com deficiências que tinham interesse de ingressar, permanecer e dar continuidade à sua escolarização na Educação de Jovens e Adultos, tendo em vista que as escolas que ofertam a EJA, não estavam preparadas para receber alunos com deficiência. Questionamos que as dificuldades encontradas atingem de diferentes modos os educandos, devido as suas deficiências e condições de vida, as escolas, e, também, os professores que atuam nessa modalidade, já marcada por tantas demandas e individualidades.

Consideramos o tema relevante, pois essa é uma realidade encontrada pelos profissionais da educação cotidianamente e que ainda é pouco discutida, pois é relativamente recente a presença de alunos público-alvo da educação especial na 
EJA, e devido a isso, neste estudo pretende-se trazer um breve levantamento sobre a relação entre as modalidades.

Destacamos a atualidade do tema, tendo em vista o cenário atual, hoje marcado por retrocessos e desmontes das políticas educacionais e pela redução no direito à educação, que atinge mais intensamente o público-alvo da educação especial e da EJA, além de outros sujeitos - indígenas, quilombolas, povos do campo, da floresta, ribeirinhos, entre outras minorias - que integram ampla parcela da população excluída historicamente da escolarização.

\section{FORMAÇÃO DE PROFESSORES E OS DESAFIOS DA INCLUSÃO NA}

\section{EJA}

A Educação Inclusiva nas redes públicas vem sendo implementada de forma paulatina, desde meados da década passada, mas esse processo se intensificou, a partir de 2016, com a criação da Lei Brasileira de Inclusão[3]. A Lei № 13.146/2015, em seu Art. 28, inciso I, incumbiu o poder público de assegurar "sistema educacional inclusivo em todos os níveis e modalidades, bem como o aprendizado ao longo de toda a vida". (BRASIL, 2015). Destacamos que "todos os níveis", inclui a educação como um todo: educação infantil, ensino fundamental, ensino médio, e ensino superior e, também, a EJA, modalidade presente no ensino fundamental e médio.

A adoção da perspectiva inclusiva na educação é uma luta que vem dos anos 1990, alavancada por convenções internacionais[4], e que constitui um grande avanço na inclusão de pessoas com deficiência na sociedade.

O princípio básico deste modelo é que todos os alunos, independentemente de suas condições socioeconômicas, raciais, culturais ou de desenvolvimento, sejam acolhidos nas escolas regulares, as quais devem se adaptar para atender às suas necessidades, pois se constituem como os meios mais capazes para combater as atitudes discriminatórias, e, como consequência,

RC: 84481

Disponível em: https://www.nucleodoconhecimento.com.br/educacao/inclusiva-confluencias 
construindo uma sociedade mais inclusiva e atingindo a educação para todos. (UNESCO, 1994 apud GLAT, 2007, p. 16 - grifo do autor)

Hoje a Educação de Jovens e Adultos (EJA) é uma modalidade que tem recebido, de forma crescente, alunos público-alvo da Educação Especial. Entretanto, apesar da ampliação da demanda, a relação entre a EJA e a Educação Especial ainda não é um objeto de estudo privilegiado pelas pesquisas em educação, no contexto da educação inclusiva, o que torna urgente pensar essa interrelação considerando suas características.

Nesse sentido, este trabalho tem como objetivo analisar o que dizem os estudos sobre a relação dos professores com inclusão educacional de jovens e adultos com deficiências. Não temos a pretensão de fazer um estudo da arte sobre o tema, mas de trazê-lo para o debate, chamando a atenção para a sua emergência, a partir de uma breve revisão da literatura e análise da legislação vigente (HENRIQUES; SIMÕES, 2017).

Este texto pretende, à luz dos estudos analisados: i - ampliar a reflexão sobre como historicamente e legislativamente ocorre a inserção dos estudantes jovens e adultos, público-alvo da educação especial, na EJA; ii - identificar as dificuldades dos professores no cotidiano processo de inclusão; iii - apresentar algumas possíveis estratégias para efetivar a inclusão.

Assim, busca-se entender em que momento percebemos a inclusão na EJA e os direitos garantidos ou desprezados nesse processo, em tentativa de compreender as experiências vividas em sala de aula pelos professores da área diante desta "nova" realidade. Para tal, formulamos a seguinte questão problematizadora: Como a Educação de Jovens e Adultos pode se preparar para receber a demanda advinda da política de inclusão, pensando ainda quais são as maiores dificuldades encontradas pelos docentes? Partimos, ainda, da hipótese inicial de que para que a EJA possa se tornar uma modalidade inclusiva e atender adequadamente esse "novo" público é

RC: 84481

Disponível em: https://www.nucleodoconhecimento.com.br/educacao/inclusiva-confluencias 
importante investir na formação continuada de professores articulando essas duas modalidades: EJA e Educação especial na perspectiva inclusiva.

É preciso pensar em como a EJA como um todo pode adequar-se para receber esses alunos, tendo em vista ser uma modalidade caracterizada pela diversidade de público e que também enfrenta cotidianamente uma série de dificuldades, que reforçam históricos processos de precarização e exclusão.

Consideramos que investir na formação dos profissionais é um elemento determinante para inclusão, como garante a Lei 9394/96 em seu artigo 59 inciso III, ao determinar que os sistemas de ensino assegurarão professores especializados e capacitados para atender os estudantes com deficiência (BRASIL, 1996). Entretanto, para ser inclusiva a escola não depende somente do professor, a quem hoje se responsabiliza quase que exclusivamente pelo desempenho dos estudantes, sem considerar que o Estado nem sempre fornece condições favoráveis de trabalho. Faz-se necessário que haja uma mudança de mentalidade, uma reformulação total do modo de pensar e agir da sociedade, das escolas e seus profissionais, incluindo os gestores, docentes e técnicos, sem esquecermos o imprescindível investimento em formação e equipamentos, previstos na legislação, mas muitas vezes sem efetivação nas políticas públicas.

Assim, tendo em vista o cenário atual, podemos inferir que a formação de professores para a Educação Especial em EJA deveria merecer mais atenção, já que na formação inicial, muitos cursos sequer abordam de forma obrigatória as duas modalidades, sendo o conhecimento sobre elas (EE e EJA) o primeiro passo para a interação dadas suas características tão específicas. É necessário conhecer esse público e suas demandas para que se possa adequar o ensino para suas necessidades, visando sua autonomia e emancipação. Esta é uma tarefa de toda a escola, e não apenas do professor, como afirma Glat (2007, p. 16):

RC: 84481

Disponível em: https://www.nucleodoconhecimento.com.br/educacao/inclusiva-confluencias 
Para tornar-se inclusiva a escola precisa formar seus professores e equipe de gestão, rever as formas de interação vigentes entre todos os segmentos que a põe e que nela interferem. Precisa realimentar sua estrutura, organização, seu projeto político pedagógico, seus recursos didáticos, metodologias e estratégias de ensino, bem como suas práticas avaliativas. Para acolher todos os alunos, a escola precisa, sobretudo, transformar suas intenções e escolhas curriculares, oferecendo um ensino diferenciado que favoreça o desenvolvimento e a inclusão social. (GLAT, 2007, p. 16).

O ingresso do aluno com deficiência na escola foi uma conquista importante, um avanço, porém não é suficiente para a garantia da inclusão e o aprendizado escolar, pois a socialização favorecida com o ingresso é apenas o primeiro passo para a inclusão. Partindo do entendimento que a inclusão é um processo, para que se efetive e saia do papel, é necessário um trabalho coletivo de todos os envolvidos, como: responsáveis, professores, educandos e demais funcionários.

Não podemos esquecer o papel fundamental do professor para a efetivação da perspectiva inclusiva, mas o mesmo para se preparar para essa realidade precisa tomar consciência de que "onde há vida, há inacabamento" (FREIRE, 2018, p. 50), um conceito que reforça a necessidade de estarmos sempre em um estado de busca constante. Nesse sentido, os educadores precisam atualizar-se, de forma contínua partindo do pressuposto que a formação é permanente.

Professores não são detentores do saber, pois é aprendendo que aprendemos a ensinar e precisamos dar ao aprender sua devida importância. É válido ressaltar que se aprende o tempo todo na interação com o educando, inclusive é sabendo escutar que conhecemos melhor nossos discentes e é quando conhecemos suas singularidades, especificidades, dificuldades etc. (FREIRE, 2011)

Sabemos que a inclusão, infelizmente, ainda não é uma realidade em todas as escolas brasileiras, e que a perspectiva inclusiva, hoje, sofre ameaças de retrocessos, porém "sei que as coisas podem até piorar, mas sei também que é possível intervir para melhorá-las" (FREIRE, 2018, p. 52).

RC: 84481

Disponível em: https://www.nucleodoconhecimento.com.br/educacao/inclusiva-confluencias 
Dentre outros empecilhos que dificultam e surgem durante o processo, não podemos deixar de destacar que os parcos investimentos em educação, e os recentes cortes de recursos, afetam em especial as modalidades que atendem ao público historicamente excluído da escolarização, a saber a EJA e a Educação Especial, entre outras, configurando um intenso retrocesso nas políticas públicas educacionais. (SILVA; LOPES; LINO, 2018)

Assim, é necessário dar a devida importância à formação inicial e continuada para os professores e todo o corpo escolar que contemplem o atendimento a esse público, o que obriga a estabelecer uma relação entre as modalidades citadas: EJA e EE. Além disso, julgamos ser essencial, o desenvolvimento de pesquisas sobre a temática para começar a pensar em como fazer dar certo a perspectiva inclusiva na Educação de Jovens e Adultos.

\section{EJA EM UMA PERSPECTIVA INCLUSIVA: BREVE CONTEXTUALIZAÇÃO HISTÓRICA E LEGAL}

Visando contextualizar melhor o problema em questão, realizamos um levantamento da legislação sobre a educação inclusiva, a Educação especial e a EJA, e breve pesquisa bibliográfica sobre as modalidades e a perspectiva inclusiva. Assim, estabelecemos um diálogo com alguns autores que trazem contribuições tanto no campo da educação especial/educação inclusiva (GLAT, 2007; GLAT; BLANCO, 2013; GLAT; NOGUEIRA, 2003) como da Educação de Jovens e Adultos (PAIVA, 2006; JULIÃO, 2015). Buscamos um olhar inclusivo para as obras de Paulo Freire $(2018,2011,2004)$, e identificamos ainda alguns trabalhos que articulam a EJA e a Educação inclusiva e que podem auxiliar nessa discussão.

A Educação de Jovens e Adultos (EJA) e a Educação Especial (EE) são duas modalidades de ensino, que integram a Educação Básica, de acordo com a Lei de 
Diretrizes e Bases da Educação Nacional (LDB), seção V (EJA) e capítulo V (EE). (BRASIL, 1996)

A EJA é destinada a jovens, adultos e até mesmo idosos que não iniciaram ou devido a algum motivo interromperam a sua escolarização e a Educação Especial é uma modalidade que perpassa todas as outras atendendo o público das pessoas com deficiência. (SOUZA; SILVA, 2016)

A história da Educação das pessoas com deficiência e das pessoas jovens e adultas tem uma mesma marca: a exclusão e o preconceito, e o tardio acesso à escolarização. Ao longo da História, as pessoas com deficiência foram submetidas a diferentes práticas de exclusão social, que na Antiguidade chegavam até a eliminação com a morte ou o abandono. A partir da Modernidade a exclusão foi sendo substituída pela segregação[5] em instituições, que até o Século XIX, sequer ofereciam algum atendimento educacional. Abordagens pedagógicas focadas nos modelos terapêuticos, realizadas em instituições não escolares, de cunho filantrópico, hegemonizaram o atendimento 'educacional' das pessoas com deficiências, categorizando-as em tipologias, segundo critérios médicos e psicológicos.

Apenas na segunda metade do século XX começa a se esboçar um novo paradigma socioeducacional que previa a integração das pessoas aos espaços sociais, entre eles as instituições escolares. Com a abordagem educacional, a educação especial se desloca para a escola pública, ainda que de forma segregada, pois a ênfase era a integração física e espacial que permitia a segregação em classes e escolas especiais, em faixa etária condizente com a obrigatoriedade escolar, restando aos adultos apenas o atendimento nas instituições filantrópicas.

A Constituição Federal de 1988, marco no processo de democratização do país, amplia o direito à educação para todos (Art. 205), sem quaisquer formas de discriminação, sendo assegurada, como princípio, a igualdade de condições para o 
acesso e permanência na escola (Art. 206). Destaco que, no Art. 208, se explicita que o acesso ao ensino obrigatório e gratuito é um direito público subjetivo $\left(\S 1^{\circ}\right)$ e que o dever do Estado com a oferta gratuita e obrigatória da educação básica para todos será efetivado mediante a garantia: de oferta a todos os que a ela não tiveram acesso na idade própria (inciso I); ao atendimento educacional especializado aos portadores de deficiência, preferencialmente na rede regular de ensino (inciso III); e a oferta de ensino noturno regular, adequado às condições do educando (inciso VI). (BRASIL, 1988)

Apenas em meados dos anos 1990, acompanhando movimento mundial, é que a perspectiva inclusiva começa a ser discutida, no Brasil, em substituição a concepção integracionista, tornando-se alvo da política educacional na década seguinte. (UNESCO, 1990; UNESCO, 1994)

Da mesma forma a EJA, tardiamente foi alvo de políticas educacionais, que incluíram a modalidade na educação básica, com a LDB (Lei 9394/1996). O reconhecimento tardio da dívida social com alunos que não tiveram acesso à escolarização na infância, a chamada 'idade certa', ou que foram excluídos da escola pelo fenômeno da evasão escolar, que marca os processos de exclusão que a reprovação escolar amplia.

Como explicita Bastos (2011, p. 18), vive-se em uma sociedade em que "saber ler, escrever e reconhecer números" além de cálculos básicos são exigências mínimas "para consolidar a cidadania e suprir suas necessidades básicas através do seu trabalho, necessitando, além disso, o letramento" sabendo fazer usos da língua em seu cotidiano. Sem esses conhecimentos o sujeito acaba sendo excluído de uma participação ativa, necessitando assim da inclusão a partir de aprendizado.

Recorrendo aos estudos que abordam a EJA e a Educação especial/Educação Inclusiva (EE/EI) de maneira conjunta, neste trabalho, buscamos estabelecer uma relação entre ambas as modalidades. Já que a educação especial passa por todos os

RC: 84481

Disponível em: https://www.nucleodoconhecimento.com.br/educacao/inclusiva-confluencias 
níveis se integrando à proposta político pedagógico da escola, veremos que em algum momento a EE e a EJA devem se entrelaçar. Com o encontro dessas modalidades de forma mais frequente, devido a política de inclusão, as pesquisas nessa área tiveram um aumento, porém ainda não são suficientes para, por exemplo, pensar na preparação do professor que atua nessa realidade, nem mesmo na sua formação inicial.

Segundo Trentin (2017), entre 2008 e 2015, apenas 19 pesquisas no Brasil contemplavam essa temática nas modalidades de pós-graduação[6]. Portanto, se é através das pesquisas/teorias que nos preparamos para as realidades enfrentadas no nosso cotidiano ainda há um longo caminho a ser percorrido.

Segundo dados apresentados por Souza e Silva (2016), o fato de ter alguma deficiência no Brasil resulta em duas vezes mais chances de não frequentar a escola e nem ser alfabetizado entre 7 e 14 anos, além de ter quatro vezes mais chances de não ser alfabetizado entre 13 e 17 anos. Ou seja, percebemos grandes chances dessas pessoas chegarem a EJA. (UNICEF, 2003 apud SOUZA; SILVA, 2016) O Censo do IBGE/2010, informa que $61,1 \%$ da população de 15 anos ou mais com algum tipo de deficiência não tinham instrução ou possuíam apenas o Ensino Fundamental incompleto, enquanto pessoas da mesma faixa etária sem deficiência totalizavam um percentual de 38,2\%. (SOUZA; SILVA, 2016)

Souza e Silva (2016) apontaram como possível solução para melhoria no atendimento das pessoas com deficiência na EJA, visando principalmente assegurar sua permanência, seria a implementação do Atendimento Educacional Especializado AEE no mesmo turno, e não no contraturno como é proposto para as crianças. No período noturno, quando funcionam a maioria das turmas de EJA, o AEE é quase inexistente, inviabilizando $O$ atendimento das especificidades e necessidades dos estudantes que precisam desse apoio. Assim, cursando menos disciplinas, mas com o apoio do AEE no mesmo turno, seria possível uma melhor qualidade e 
aproveitamento na sua escolarização, além de "assegurar a sua inserção no mundo do trabalho" (SOUZA; SILVA, 2016, p. 61). Dessa forma, os alunos não precisariam escolher entre uma inclusão escolar ou social e cidadã.

Essas questões precisariam ser bem pensadas, pois a EJA ainda traz as marcas da característica supletiva, de aceleração, mas pensando em Paulo Freire (2011) e respeitando o tempo de aprender de cada sujeito, essa possibilidade "atrasaria" um pouco quem precisa, mas o prognóstico se tornaria mais satisfatório.

Contudo, segundo as autoras existem muitos desafios para efetivação dessas ideias, dentre eles: seria preciso um grupo de "profissionais multidisciplinares"; a ampliação de salas de recurso e com isso a ampliação do atendimento; além de profissionais para atuar nesses espaços; articulação de formações continuadas entre os professores de sala de recurso, regentes, coordenadores, orientadores e demais profissionais que atendam essa demanda; e a garantia de adaptações e adequações físicas e curriculares para o público em questão. (SOUZA; SILVA, 2016)

Entretanto, para que tudo isso possa ser garantido, é preciso planejamento, políticas públicas, financiamento e apoio inclusive de outros âmbitos, em articulação intersetorial, como saúde, esporte, assistência social, entre outras áreas, pois é um trabalho complexo. Atentar para a complexidade da educação inclusiva, principalmente assegurando o apoio e as adaptações necessárias, ou seja, é preciso ter mais atenção para acessibilidade, AEE e sua ausência, adequações no currículo, formação e valorização docente.

\section{O PNE, SUAS METAS E A INCLUSÃO}

Dentro do esforço de contextualização, cabe analisar a Lei 13.005/2014, que institui o Plano Nacional de Educação (PNE), focalizando especificamente as metas e estratégias pertinentes à EJA, Educação Especial, Valorização dos Profissionais da 
Educação. O PNE direciona esforços e investimentos para avanços na qualidade da educação brasileira, estabelecendo metas, diretrizes e estratégias que visam garantir o direito à educação básica de qualidade (ampliação da escolaridade), a valorização da diversidade e dos profissionais da educação, a elevação da qualidade da educação e matrículas no ensino superior. Consideramos o financiamento é uma condição fundamental para o cumprimento das metas, a cargo dos governos federal, estadual e municipal, de forma articulada, com o acompanhamento da sociedade. (BRASIL, 2014)

Dentre as 20 metas do PNE, destacamos as metas 4, 9, 10, 18 e 20, atinentes à EJA, EE, Valorização Docente e ao financiamento. A meta 4 carrega as estratégias para assegurar a implantação de salas de recursos multifuncionais, fomentar a formação continuada dos docentes para o atendimento educacional especializado nas escolas e promover uma articulação dos setores entre os órgãos e políticas públicas, a fim de desenvolver modelos de atendimento voltados à continuidade da escolarização de jovens e adultos com deficiência. (BRASIL, 2014)

A meta 9 traz a estratégia para diminuição do analfabetismo e a maior oferta pública para escolarização dos jovens e adultos, que não conseguiram cursar o ensino fundamental na idade considerada apropriada. A meta 10 complementa a anterior com estratégias para aumento de matrículas, as quais ainda não são suficientes, na EJA, para atender todo o público, trazendo ainda a integração à educação profissional. (BRASIL, 2014)

A número 18 tem o intuito de assegurar a existência de planos de carreira para os profissionais da educação básica e superior pública para com isso valorizar a profissão e despertar o interesse pela formação em cursos de licenciatura. E por fim, a meta 20, especificamente voltada para o financiamento, determina os investimentos repassados para Educação Básica, sendo em 2012 de 6,4\% do PIB (Produto Interno Bruto), devendo este ser aumentado para no mínimo 7\% no quinto ano de vigência 
dessa lei, isto é, em 2019, e o equivalente a 10\% do PIB ao final do décimo ano (2024). Além desta aplicação, a Constituição Federal de 1988, art. 212, dispõe que a União aplicará, ao ano, nunca menos de 18\%; e os estados, Distrito Federal e os municípios 25\% no mínimo, da receita resultante de impostos, para manutenção e desenvolvimento do ensino. (BRASIL, 2014)

Para o alcance de todas as metas citadas, dentre outras presentes no documento, 0 investimento é visivelmente fundamental para valorização do profissional da educação, a ampliação do acesso e permanência dos alunos, e a manutenção e desenvolvimento da educação com qualidade. Mas como exposto anteriormente, a aprovação da Emenda Constitucional 95/2016 que impôs um Novo Regime Fiscal ao país, houve um congelamento dos gastos públicos por vinte anos, principalmente os investimentos voltados para saúde e educação, vivenciando assim o retrocesso. $\mathrm{Na}$ prática a EC 95/2016, ao reduzir os investimentos na educação, além de não garantir os recursos necessários para sua oferta com qualidade, inviabilizou o cumprimento do PNE. (SILVA; LOPES; LINO, 2018)

\section{A EJA INCLUSIVA}

Ainda com o intuito de pensar sobre a realidade da "EJA inclusiva" retomamos a reflexão de Trentin (2017), a partir da implementação da Política Nacional de Educação Especial na Perspectiva da Educação Inclusiva (entre 2008 e 2013), por meio de dados do Censo Escolar da Educação Básica divulgados pelo Instituto de Estudo e Pesquisas Educacionais Anísio Teixeira (INEP) que indicam um aumento de 26.557 em 2003 para 114.905, estudantes com necessidades especiais matriculados na EJA em 2015, crescimento equivalente a $333 \%$. Com isso, houve uma mudança no público atendido pela EJA, que antes eram apenas aquelas pessoas que não tiveram oportunidade de escolarização na idade apropriada, e que agora também abrange aquelas que mesmo escolarizadas, não tiveram aprendizagens suficientes para o desenvolvimento e participação social plena.

$\mathrm{RC}: 84481$

Disponível em: https://www.nucleodoconhecimento.com.br/educacao/inclusiva-confluencias 
Hoje já é possível encontramos alguns estudos que tratam do público-alvo da educação especial na EJA, ampliando o debate sobre os desafios para a inclusão destes alunos e para a atuação dos professores na modalidade, como os trabalhos de Trentin (2017), Souza e Silva (2016) e Beras e Filho (2015). Alguns trabalhos tratam da perspectiva da ampliação do direito à educação para jovens e adultos com deficiência como os de Moreira (2014), Gonçalves, Bueno e Meletti (2013) e Bastos (2011), e outros de propostas de intervenção, como o de Barbosa e Franco (2017).

Consideramos que, em meio a retrocessos e desmontes em curso na educação brasileira, e mais especificamente, que reduzem o direito à educação do público-alvo da Educação Especial e da EJA, entre outros tantos ataques, reafirmar a busca pelo conhecimento nos possibilita esperançar, como afirma Freire (2018).

A EJA é uma modalidade que visa superar a dívida social não reparada para aqueles que não tiveram acesso à escolarização e oportunidades de permanência. Apenas recentemente, isto é, há menos de três décadas, tornou-se alvo de políticas públicas e foi inserida no sistema educacional. Sabemos que a conquista de direitos é um processo longo, lento e que exigiu muita luta e organização, até que estes fossem assegurados pela legislação (BRASIL, 1988; 1989; 1996; 2001; 2007; 2014). Assim, consideramos importante destacar, ainda que brevemente, o que algumas Declarações, Pareceres e Diretrizes dizem.

Com relação à legislação começaremos com a Constituição Federal 1988 que em seu artigo 208, garante a educação básica obrigatória e gratuita[7] para todos que não tiveram acesso na idade própria, como obrigatoriedade do Estado. As pessoas que não estão com a idade considerada apropriada são encaminhadas a EJA, podendo usufruir de todas as prerrogativas legais, incluindo a oferta do Atendimento Educacional Especializado (AEE), para pessoas com deficiência. (MOREIRA, 2014)

RC: 84481

Disponível em: https://www.nucleodoconhecimento.com.br/educacao/inclusiva-confluencias 
O Brasil é signatário em uma série de Convenções e tratados internacionais que abordam a questão da inclusão das pessoas com deficiência, como a Convenção de Jointiem (1990), a Declaração de Salamanca (1994) e a Convenção de Guatemala (2001). A Declaração Mundial de Educação para Todos (JOMTIEN, 1990), em seu art. $1^{\circ}$ determina que cada pessoa tem o direito de satisfazer suas necessidades básicas e essenciais para a aprendizagem, e assim "desenvolver plenamente suas potencialidades, viver e trabalhar com dignidade, participar plenamente do desenvolvimento, melhorar a qualidade de vida, tomar decisões fundamentadas e continuar aprendendo", sendo esta, uma responsabilidade e um compromisso dos Governos e da sociedade. (UNESCO, 1990) A Declaração de Salamanca (1994) desencadeou um processo mundial de mudanças em políticas públicas destinadas a garantir o direito à educação de grupos sociais em situação de desvantagem e risco contínuo de exclusão. (MOREIRA, 2014) A Convenção de Guatemala (2001), aprovada na Convenção Interamericana para a eliminação de todas as formas de discriminação contra as pessoas portadoras de deficiência, foi promulgada no Brasil, pelo Decreto 3.956/2001.

De acordo com a Resolução CNE/CEB nํ 2/2001, as Diretrizes Nacionais para a Educação Especial na Educação Básica, as escolas devem matricular todos os alunos independentemente das suas características ou especificidades. Importante destacar que cabe à escola se organizar para atendê-los, ou seja, não são as crianças que precisam adaptar-se à escola, pelo contrário a mesma que deve garantir uma educação de qualidade para os educandos, atendendo as necessidades educacionais de todos.

No Brasil, a mudança paradigmática se deu, em definitivo, com a Política Nacional de Educação Especial na Perspectiva da Educação Inclusiva (2008) que propõe uma ampliação de conhecimentos, métodos e processos na escolarização das pessoas com deficiência, incluindo o Atendimento Educacional Especializado (AEE), serviço 
esse que identifica, elabora e organiza recursos pedagógicos e de acessibilidade. (SOUZA, 2016)

De acordo com as Diretrizes Curriculares Gerais para a Educação Básica (RES CNE/CEB no4/2010), deve haver o respeito aos educandos e aos seus tempos mentais, socioemocionais, culturais e de identidade, que é o princípio da ação educativa, independentemente da idade, sem descartar que é importante a oportunidade de receber a formação que corresponda a sua faixa etária. (MOREIRA, 2014)

Como vimos, anteriormente, o Plano Nacional de Educação 2014-2024, trouxe avanços consideráveis na ampliação do direito à educação, com metas e estratégias que visam a elevação da qualidade do ensino para todas as modalidades. Entretanto, a Emenda Constitucional 95/2016 que congelou os gastos, dentre esses os da saúde e educação, comprometeu a materialização desses avanços.

É possível perceber, que não podemos nos limitar a focar somente no acesso à educação, precisamos pensar na permanência e êxito dos estudantes que estão na EJA, uma modalidade com um público tão diversificado. Cabe considerar a diversidade de sujeitos da EJA- trabalhadores, com privação de liberdade, das populações rurais, jovens, idosos e recentemente com a inclusão, pessoas com deficiência e as especificidades de cada um (JULIÃO, 2015). Apenas assim é possível garantir a todos o direito à educação e reafirmar a EJA como modalidade inclusiva, incluindo mais um grupo historicamente excluído: as pessoas com deficiência.

Como explicita Bastos (2011, p. 6) se a sociedade fosse "verdadeiramente ética, não seria necessário tantas leis para garantir que a sociedade trate com justiça e equidade àqueles que dela necessitam de um olhar diferenciado", visto que a equidade é "tratar diferente aqueles que são diferentes" com igualdade em oportunidades. Se tratando da EJA inclusiva é preciso conviver para aprender a lidar com as diferenças, não basta 
uma disciplina escolar para ensinar o respeito é preciso conhecimento e convívio com a diversidade.

E esses são apenas alguns dos desafios postos, comuns tanto para a EJA quanto para a Educação Especial. Ainda há um longo caminho para se pesquisar e conhecer, porém já percebemos que essas modalidades se encontram na legislação e que devem estar articuladas, pois não podemos tratá-las de forma isolada, diante da política de inclusão que vinha sendo implementada, e que hoje está ameaçada.

\section{ESCOLA INCLUSIVA / A ESCOLA EM MEIO A INCLUSÃO}

A inclusão de estudantes com deficiência nas classes regulares tem se tornado uma questão constantemente presente no debate educacional. De acordo com Beras e Filho (2015, p. 12682) esses debates devem "refletir acerca das demandas de um alunado que apresenta especificidades e possui o direito ao acesso e à permanência na escola regular", logo observa-se que a modalidade que tratamos nesse trabalho e seu público atendido, também se encaixa nessa reflexão.

A educação inclusiva é uma abordagem que visa auxiliar e responder às necessidades de aprendizagem de todos os alunos independente da faixa etária que se encontram, segundo Beras e Filho (2015). Os autores ressaltam ainda que o foco deve estar nas pessoas "que estão excluídas da efetivação do direito à educação e que estão fora da escola ou enfrentam barreiras para participação nos processos de aprendizagem escolar" (BERAS e FILHO, 2015, p. 12682). Ou seja, a EJA é também "inclusiva”, pois quase todos os estudantes se enquadram nessas particularidades e agora com a demanda de pessoas com deficiência é preciso pensar em um trabalho duplamente inclusivo com esses educandos.

Portanto, a perspectiva inclusiva exige uma mudança de postura das escolas, pois são elas que precisam se adaptar para acolher os estudantes e promover a inclusão.

RC: 84481

Disponível em: https://www.nucleodoconhecimento.com.br/educacao/inclusiva-confluencias 
De acordo com Barbosa (2017 p. 4) as escolas inclusivas são algo novo e as que conseguem minimamente alcançar a participação de todos tem sido objeto de estudo para servir de exemplo a outras. Podemos citar como exemplo, Barbosa (2017) que traz uma proposta para inclusão escolar para alunos com deficiência intelectual e/ou autismo e defasagem idade/série no Distrito Federal, que seriam classes especiais de "EJA Interventiva" em escolas regulares de Educação de Jovens e Adultos. A proposta permitiria uma maior flexibilidade no tempo (podendo estender as etapas), na avaliação, nas metodologias e tudo o que for necessário para melhor aproveitamento dos alunos com necessidades específicas.

Entretanto, ainda há um grande caminho a percorrer, por mais que seja um projeto bem-sucedido ainda assim existe a necessidade de suprir as enormes carências que dificultam a inclusão com aprendizagem das pessoas com deficiência dentro de salas regulares. Muitas são as demandas dos professores frente ao desafio de ministrar um ensino de qualidade para pessoas tão distintas, com necessidades específicas e turmas cheias.

Beras e Filho (2015) apontam que a EJA no início visava à suplência, o suprimento, a aprendizagem e a qualificação dos estudantes, e era ofertada em forma de cursos e exames supletivos, em um caráter hoje superado. Com a "atual" demanda de alunos incluídos, não basta apenas suprir o tempo perdido ou complementar algo que faltou para conclusão dos estudos, mas sim prepará-los para prática cidadã.

Cidadania esta que Paulo Freire (2011) nos ensina como uma forma de resgatar "[...] a decência, a afirmação de si como gente, o exercício ético, a possibilidade de intervenção na realidade, a escolha pelo coletivo [...]" e principalmente o fazer parte da "[...] construção possível do sonho de uma sociedade cada vez menos desigual" (VASCONCELOS; BRITO, 2019, p. 52). O que nos faz entender que precisamos aprender para sermos mais participativos na sociedade em que vivemos.

RC: 84481

Disponível em: https://www.nucleodoconhecimento.com.br/educacao/inclusiva-confluencias 
É preciso mudar a forma de ver a pessoa com deficiência, para estabelecermos uma melhor relação com elas e com isso adotarmos uma postura em que buscaremos a equiparação de oportunidades. Essa é a forma de preparar a sociedade para receber esse cidadão/cidadã, minimizando prejuízos pessoais e sociais. (GLAT; NOGUEIRA, 2003, p.137)

Para Beras e Filho (2015), a superação de barreiras e o bom aproveitamento do estudo pelos alunos com deficiência da EJA requerem não somente o apoio do AEE - Atendimento Educacional Especializado[8], mas também do trabalho em equipe dos professores de classe regular com o professor de AEE, além dos profissionais que estão no interior da escola fazendo parte do processo de inclusão. A produção de recursos pedagógicos que auxiliam na aprendizagem também é preponderante. Acredita-se que para os demais alunos da EJA, seria importante, também uma forma de reforço para os que tivessem mais dificuldades na escolarização, ampliando o potencial inclusivo presente na modalidade.

Segundo a Política Nacional de Educação Especial na Perspectiva da Educação Inclusiva (2008) o AEE está presente nas escolas para disponibilizar

programas de enriquecimento curricular [...] que usufruem de ajudas técnicas e tecnologia assistiva, dentre outros. Ao longo de todo processo de escolarização, esse atendimento deve estar articulado com a proposta pedagógica do ensino comum. (BRASIL, 2008)

Para analisar a implementação e funcionamento da política, no que tange o AEE, um levantamento dos dados disponibilizados pela Secretaria Municipal de Educação, apontou que no Município do Rio de Janeiro existem em torno de 424 salas de recursos multifuncionais, que é onde acontece o AEE dos alunos com deficiência, divididas por Coordenadorias Regionais de Educação- CRE[9]. Na Primeira CRE são em média 20 escolas com salas de recursos; a segunda CRE são em média 33 escolas; a terceira CRE 49; a quarta CRE 39; a quinta CRE 55; a sexta CRE 43; a 
sétima 59 escolas; a oitava 40 unidades; e a nona, a décima e a décima primeira são respectivamente 47, 29, e 10 unidades com salas de recursos multifuncionais[10].

Segundo o Manual de Orientação: Programa de Implantação de Sala de Recursos Multifuncionais (BRASIL, 2010, p. 9), os objetivos das salas de recursos são em resumo: apoiar a organização da Educação Especial na perspectiva inclusiva; assegurar o acesso dos alunos da EE no ensino regular; disponibilizar recursos pedagógicos e de acessibilidade às escolas da rede pública; e promover desenvolvimento profissional e participação da comunidade escolar. $O$ documento explicita que as salas de recursos multifuncionais devem manter seu efetivo funcionamento, com oferta do [...] AEE aos alunos alvo da educação especial matriculados em classe comum de ensino regular". (BRASIL, 2010, p. 3). Em conformidade com a LDB, o AEE deve ser "gratuito aos educandos com deficiências [...], transversal a todos os níveis, etapas e modalidades, preferencialmente na rede regular de ensino" (BRASIL, 1996), entretanto, o Manual apresenta a oferta do AEE no turno oposto ao ensino regular, porém sem dar obrigatoriedade estrita a esse feito, deixando implícito que cabe a escola a organização dos horários desse atendimento. (BRASIL, 2010, p. 6)

Ainda, segundo o Manual de Orientação (2010), as escolas selecionadas precisam estar dentro dos critérios para implantação das salas os quais são: a Secretaria de Educação referente à escola precisa ter elaborado um Plano de Ações Articuladas registrando as demandas com base no diagnóstico da realidade educacional da mesma; a escola indicada deve ser da rede pública de ensino, deve ter alunos da Educação Especial matriculados regularmente em classes comuns para implantação da sala Tipo I[11] ou alunos cegos para implantação da sala Tipo II[12]; além de a escola precisar de um espaço físico adequado para o funcionamento da sala e um profissional para atuar no AEE.

RC: 84481

Disponível em: https://www.nucleodoconhecimento.com.br/educacao/inclusiva-confluencias 
No AEE, os alunos deveriam ser atendidos individualmente ou em pequenos grupos, de acordo com suas necessidades específicas. (BRASIL, 2010) O Manual de Orientações (2010), indica que, além do espaço físico adequado em condições de acessibilidade e materiais pedagógicos, são requeridos professores com formação para atuação na sala de recursos, profissionais de apoio quando necessário e também um trabalho em equipe desses profissionais com os professores de sala regular, além da formação continuada para toda equipe escolar. A participação da família e o apoio com acompanhamento dos serviços públicos de saúde, assistência, entre outros, são aspectos relevantes. E Por fim, a oferta desse atendimento é para os alunos matriculados no ensino regular da própria escola e de outras escolas da rede pública, sempre atualizando o registro anual no Censo Escolar das matrículas no AEE.

Em relação às escolas que oferecem PEJA - Programa de Educação de Jovens e Adultos no município do Rio de Janeiro[13], do total de escolas também divididas por CRE que são 143 unidades com oferta de EJA mais o CREJA[14], tornando-se um total de 144, sendo que 81 oferecem salas de recursos incluindo o CREJA, totalizando 82. Dados de acordo com a Relação de Escolas que oferecem EJA (2019) e a Relação de Escolas que oferecem Salas de Recursos (2019).

Ao entrar em contato com algumas escolas constatou-se que é preciso passar pela CRE para que a mesma encaminhe o aluno com deficiência para escola com sala de recursos. Entretanto, das escolas que forneceram informação sobre horários de atendimento da sala de recursos, nenhuma tem atendimento à noite, algumas tem manhã e tarde, outras somente manhã e até mesmo algumas que não sabem o que é "sala de recursos para AEE"[15]. Assinalamos que o Manual de Orientação (BRASIL, 2010) é omisso quanto a oferta de horários do AEE, e assim, as escolas visando a questão do contraturno ao ensino regular organizam seus horários de atendimento junto aos professores, podendo optar por escolher dentre os três turnos.

RC: 84481

Disponível em: https://www.nucleodoconhecimento.com.br/educacao/inclusiva-confluencias 
Contudo, seria possível e até mesmo preciso repensar esses horários para atender melhor os alunos da EJA que precisem do Atendimento Educacional Especializado à noite, caso trabalhem ou até mesmo para quem os acompanhem precise trabalhar durante o dia e não tem como acompanhá-los nos horários existentes. Acreditandose assim que facilitaria ainda mais o processo de inclusão.

O Censo Escolar da Educação Básica (2018) nos mostra que mesmo o crescimento de pessoas com deficiência na EJA não seja o maior e nem ultrapasse, por exemplo, o aumento de matrículas no ensino fundamental e médio, ainda assim detectou-se um aumento no número de matrículas, que passaram de 111.963 em 2014 para 130.289 em 2018, que em percentual equivale a 9,4\% estudantes com deficiência na EJA.

Porém quando se trata dos alunos que estão matriculados em classes regulares atendidos pelo AEE, o Censo Escolar da Educação Básica (2018) só traz informações dos alunos com idades de 4 a 17 anos, que não é o público-alvo da EJA, e mesmo assim menos da metade são atendidos com o AEE. Sendo que o número de matrículas de alunos público--alvo da Educação Especial em classes regulares está cada vez maior e as classes especiais cada vez em menor número, mesmo sem atendimento educacional especializado para todos.

De acordo com Beras e Filho (2015), o AEE funciona como uma forma de auxílio positivo da vida acadêmica dos estudantes e, além disso pode servir como uma mediação da aprendizagem do sujeito que frequenta esse espaço. O professor de sala de recursos deverá ter curso de "graduação, pós-graduação e ou formação continuada" (BERAS e FILHO, 2015, p. 12686) que habilite para atuar nesse âmbito, além de:

desenvolver conhecimentos acerca de: Comunicação Aumentativa e Alternativa, Braille, Orientação e Mobilidade, Soroban, LIBRAS, Ensino de Língua Portuguesa para Surdos, Atividades da Vida Diária, Aprofundamento e Enriquecimento Curricular (BERAS e FILHO, 201, p. 12686).

RC: 84481

Disponivel em: https://www.nucleodoconhecimento.com.br/educacao/inclusiva-confluencias 
Mesmo que não seja, o foco desse trabalho, o AEE é uma das estratégias apontadas, por estudos, que facilitam a inclusão, favorecendo a permanência das pessoas com deficiência.

Remetemos a formação de professores, tendo em vista que o professor se insere no entre lugar dos aprendizados curriculares da sala de aula regular e da relação dessas aprendizagens com 0 mundo, sendo assim 0 mediador, que torna esses conhecimentos palpáveis e com sentido, adequando-se a demanda de cada aluno. (BOCK; FURTADO; TEIXEIRA, 2008)

O AEE não serve apenas para repassar os conteúdos de forma adaptada, nele também é preciso focalizar em detalhes cotidianos que podem ser relevantes para aprimorar as práticas diárias e perceber as demandas de cada aluno incluindo atividades comuns do dia a dia, como por exemplo, amarrar os sapatos a partir do desenvolvimento da coordenação motora fina.

Entretanto, essa percepção das necessidades diárias de cada educando não está presente apenas na relação com alunos com deficiência, mas com todos os alunos da EJA. A formação para a cidadania envolve aspectos da vida diária importantes, que para a pessoa que não sabe ler, independente se tem ou não alguma deficiência, tem bastante relevância, como instruções de como pagar contas para não serem lesados por pessoas de má índole, ou até mesmo algo ainda mais simples que seria a análise de rótulos para poder selecionar os produtos da melhor forma para ter uma vida mais saudável ou para evitar agravar doenças que eles já tenham como, por exemplo, diabetes ou pressão alta.

Conhecer os alunos requer uma prática de escuta, é preciso que na fala com ele o educador seja sujeito da escuta, pois educando não é objeto de seu discurso (FREIRE, 2018, p. 111), portanto precisamos ensinar com disponibilidade para o diálogo e principalmente para uma escuta atenta às necessidades de cada sujeito. É

RC: 84481

Disponível em: https://www.nucleodoconhecimento.com.br/educacao/inclusiva-confluencias 
preciso ainda, olhar para o aluno e não ver somente os problemas e dificuldades que o rodeiam, mas sim ver neles suas potencialidades, que são sempre mais difíceis de perceber, para que com elas tenhamos um ponto de partida. Ou seja, precisamos enxergar para além da patologia ou da deficiência, e enxergar o estudante, que como qualquer outro tem limitações.

O professor, no contexto de uma Educação Inclusiva precisa, muito mais do que no passado, ser preparado para lidar com as diferenças, com a singularidade e a diversidade de todas as crianças e não com um modelo de pensamento comum a todas elas. (GLAT E NOGUEIRA, 2003, p.137)

Cabe ressaltar que os ensinamentos trocados com os estudantes precisam fazer sentido, sem ser algo tão distante da sua realidade, mas significativo, ou seja, não basta apenas repassar o conteúdo se não será útil em suas vidas, principalmente para o público que não quer mais "perder tempo" como o da EJA e nem vai fazer sentido se estiver muito distante da sua realidade como o público-alvo da Educação especial. De acordo com Beras e Filho (2015, p. 12689) "a partir do momento que o professor [...] proporciona ao aluno um novo ensinamento e estimula essa aprendizagem, o aluno apresentará os resultados [...] na maioria das vezes positivos", independentemente da sua dificuldade, mesmo que uns precisem de um pouco mais de apoio ou estímulo.

Logo, a aprendizagem e desenvolvimento são constantes na vida dos sujeitos que estamos tratando nessa pesquisa. Como afirma Paulo Freire (2018), estamos em constante aprendizado e nunca podemos perder a vontade de aprender. Entretanto, o direito à educação exige que sejam disponibilizadas mais salas recursos com atendimento educacional especializado (AEE) para as pessoas com deficiência na EJA, em horários próximos ao seu turno, e mesmo dentro do próprio turno de aula; assim como projetos de reforço escolar para os demais alunos da EJA, pois muitos também têm dificuldades. 
Com isso, facilitaria a aprendizagem de todos os educandos e a Educação de Jovens e Adultos, perderia um pouco do seu caráter ultrapassado de supletivo, tornando-se assim mais flexível para as demandas de quem precisa que seja organizado em semestres, mas também para outros que precisam um pouco mais de tempo para que o aprendizado faça sentido, no processo cognitivo de acomodação[16].

Não podemos deixar de ressaltar que a sala de recursos é um direito, uma estratégia, um recurso, e não a salvação para incluir. A Inclusão não é fácil, nem para os professores e nem para os alunos, e ainda não é um consenso entre os profissionais. Assim, é importante que se entenda que a inclusão é um processo, e não um estado, e que apenas movimentar fisicamente os estudantes, somente para que estejam presentes nas classes regulares não é o suficiente para tornar a escola inclusiva, pois eles não estarão aprendendo e nem participando ativamente da vida escolar, continuando assim excluídos dentro da inclusão.

Como podemos observar a inclusão é um processo complexo e que requer esforços e investimentos, mas podemos começar com o foco de diminuir a exclusão e ao combater a mesma aos poucos estaremos um passo mais próximo da inclusão.

É preciso comprometimento, por parte dos poderes públicos, sem promessas vãs, e sim com ações que garantam a qualidade das escolas e o seu bom funcionamento para todos, o que requer investimentos. Além da formação articulada à valorização docente, que inclui jornada e condições de trabalho, salários e plano de carreira. Sendo assim preciso inclusive repensar a profissão, para que possa ser exercida de forma digna, com carga horária suficiente e adequada para exercer e buscar formação que auxilie nas adversidades de seu cotidiano. Favorecendo assim seu trabalho, sua construção, seu planejamento e até mesmo abertura para que haja mais tempo para ouvir e conhecer seu aluno para que possa junto a ele, suprir suas necessidades.

RC: 84481

Disponível em: https://www.nucleodoconhecimento.com.br/educacao/inclusiva-confluencias 


\section{CONSIDERAÇÕES PROVISÓRIAS E INCONCLUSAS}

Não será colocado um ponto final nesse trabalho, pois ainda há um longo caminho de estudos a percorrer, principalmente, quando se trata de estar sempre buscando e estudando. Assim, este trabalho permanece inconcluso, e como podemos perceber no decorrer das páginas há muitas questões para serem debatidas sobre a articulação entre a Educação de Jovens e Adultos e a perspectiva da inclusão, que almejamos aprofundar no futuro em um estudo mais denso, analisando essa relação na realidade de sala de aula.

Destacamos ainda a necessidade de produção de mais pesquisas e estudos e aplicação dos mesmos em sala de aula, em movimento de articulação teoria-prática, buscando contribuir para o aperfeiçoamento das práticas docentes. A perspectiva inclusiva não é reduzida à educação, mas toda a sociedade deve ser inclusiva, porém em um país em que as desigualdades se acentuam e aumenta a exclusão social, esse é um desafio extremo. Assim, é importante que a educação inclusiva seja pensada de forma abrangente, como compromisso de toda a sociedade e dever do Estado.

Com isso possamos dar sentido ao conceito de cidadania para além do voto, oportunizando assim aos estudantes jovens e adultos, com ou sem deficiência, uma vida socialmente ativa e participativa, em que seus direitos sejam efetivados, contribuindo para a construção de uma sociedade mais justa e menos desigual, com oportunidades para todos.

O momento atual, de pandemia[17] da Covid-19, que obrigou o fechamento das escolas e a oferta do ensino na modalidade remota, acirrou as desigualdades educacionais e impactou bastante a oferta das duas modalidades. Durante a pandemia intensificou-se a crise política e econômica no país, que a par da crise sanitária, aumentou o desemprego e a vulnerabilidade social de amplas parcelas da população mais empobrecida. Nesse cenário, caracterizado pelo negacionismo e

RC: 84481

Disponível em: https://www.nucleodoconhecimento.com.br/educacao/inclusiva-confluencias 
insensibilidade governamental, uma série de ações legais permitiram a redução de direitos sociais, com o falso pretexto de reduzir gastos e melhorar a economia.

Infelizmente, além das dificuldades trazidas pela pandemia, um enorme retrocesso na política de inclusão se materializou com o Decreto № 10.502 de 30 de setembro de 2020, que institui a Política Nacional da Educação Especial: Equitativa, Inclusiva e com Aprendizado ao Longo da Vida. O decreto anula a perspectiva inclusiva ao instituir uma série de medidas que validam a segregação, a partir do falso entendimento de que a inclusão pode não ser benéfica para todos, alegando haver educandos que não se beneficiam com as escolas regulares inclusivas, segundo o Art. $2^{\circ}$ e inciso VI.

O Decreto fere o direito à educação para todos, sem discriminação, desrespeita a legislação e impõem uma visão retrógada de que o educando é quem precisa se adaptar à escola e não ao contrário. A retomada de concepções e práticas já superadas como as escolas regulares terem classes especiais separadas para alunos com deficiência indicada no art. 20 inciso VII e o incentivo à criação de Centros educacionais especializados presente no art. $7^{0}$ do decreto, desrespeitam a perspectiva da inclusão educacional e social e reforçam a segregação e exclusão. Indicar que a inclusão é uma escolha da família fere a Lei 8.069/1990 do Estatuto da Criança e do Adolescente (ECA), que determina o direito à matrícula na rede regular de ensino, entre outros. O documento deixa aberta a possibilidade para que o Atendimento Educacional Especializado seja um substituinte do Ensino Regular, contradizendo o que comprovam os estudos e pesquisas de que o AEE é um complemento para o ensino regular e deve ser realizado de forma concomitante. Sua concepção de 'aprendizado ao longo da vida' é equivocada e contrária ao defendido pelas associações científicas, e pelas entidades representativas de pais, professores e pessoas com deficiência. 
Diversas entidades e organizações da sociedade civil[18] se manifestaram em repúdio ao Decreto 10.502/2020, contra os retrocessos impostos à educação inclusiva, alvo de críticas de parlamentares de diversos partidos. Atendendo a ação direta de inconstitucionalidade, o ministro Dias Toffoli do Supremo Tribunal Federal (STF) suspendeu o Decreto 10.502/20, que será alvo de referendo pelo Plenário do órgão. A Constituição Federal (1988) garante o atendimento especializado às pessoas com deficiência, preferencialmente na rede regular de ensino, e que, ao assinar a Convenção Internacional sobre os Direitos das Pessoas com Deficiência, por meio do Decreto Presidencial 6.949/2009, logo, o país assumiu um compromisso com a educação inclusiva, ou seja, a educação deve agregar e acolher as pessoas com deficiência ou necessidades especiais no ensino regular, ao invés segregá-las em grupos afastados da própria comunidade[19].

O decreto além de um retrocesso educacional fere leis maiores que asseguram os diretos dos cidadãos com deficiência, e representa o descaso e a desconsideração por parte do Governo federal da opinião das pessoas com deficiências, seus familiares, movimentos sociais, e também do conhecimento científico no campo da educação produzido por Universidades e seus pesquisadores, negando a luta pela efetivação da Educação Inclusiva no Brasil.

Para dar o primeiro passo para uma sociedade inclusiva, segundo Bastos (2011), é preciso aceitar, respeitar e valorizar a diversos, mas com esses retrocessos é possível ver que mesmo a inclusão já sendo um processo longo e lento se torna ainda mais difícil quando durante o caminho ainda regredimos. Promover a inclusão no contexto da EJA inclusiva é duplamente difícil, pois enfrenta histórica segregação e duplo preconceito.

Portanto, após tantos avanços e conquistas, continua sendo necessário lutar contra os retrocessos, pois direitos arduamente conquistados devem ser preservados. Persistimos resistindo, sem desânimo, é importante seguir estudando e pesquisando,

RC: 84481

Disponível em: https://www.nucleodoconhecimento.com.br/educacao/inclusiva-confluencias 
contribuindo, assim, para a construção de uma escola e sociedade inclusiva, da ampliação do direito à educação para todos, sem discriminação, pela superação das desigualdades sociais e educacionais, pela cidadania, pela democracia e pela vida. É preciso ter esperança, porque como dizia Paulo Freire (2018) uma educação sem esperança não é educação, e não podemos cruzar os braços, porque é necessário mover-se na esperança enquanto lutamos e, se lutamos com esperança, podemos continuar e conquistar.

\section{REFERÊNCIAS}

BARBOSA, Vânia de Sousa. FRANCO, Elize Keller. EJA interventiva: Uma Proposta Alternativa de Inclusão. Revista Primus Vitam n. 9. ANAIS: II Congresso Internacional e VII Congresso Nacional de Dificuldades de Ensino e Aprendizagem. $2017 . \quad$ Disponível em: http://delphosgp.com/primus_vitam/primus_9/VaniaSousaElizeKeller.pdf Acesso em 12 de Janeiro de 2020.

BASTOS, Vívian de Cássia de Camargo. A Educação Especial no Contexto da Educação de Jovens e Adultos: Processo Duplamente Incluso. 2011. Disponível em: http://www.diaadiaeducacao.pr.gov.br/portals/pde/arquivos/1110-4.pdf Acesso em 12 de Janeiro de 2020.

BERAS, Julia Jost. FILHO, César Augusto Robaina. Educação Especial no Contexto da Educação de Jovens e Adultos (EJA): Relato de Experiência. EDUCERE - XII Congresso Nacional de Educação. ISSN 2176-1396. PUCPR, 2015. Disponível em: https://educere.pucpr.br/p1/anais.html?tipo=4\&titulo=\&edicao=5\&autor=Julia+Jost+B eras\&area $=56$ Acesso em 12 de janeiro de 2020

RC: 84481

Disponível em: https://www.nucleodoconhecimento.com.br/educacao/inclusiva-confluencias 
BOCK, Ana Mercês Bahia; FURTADO, Odair; TEIXEIRA, Maria de Lourdes Trassi. Psicologias: Uma Introdução ao Estudo da Psicologia. Editora: Saraiva. 14ª edição. São Paulo. 2008.

BRASIL. Constituição da República Federativa do Brasil. Brasília: Imprensa Oficial, 1988.

BRASIL. Coordenadoria Nacional para Integração da Pessoa Portadora de Deficiência - CORDE. Lei no 7.853, de 24 de outubro de 1989. Dispõe sobre o apoio às pessoas portadoras de deficiência e sua integração social. Disponível em: http://www.planalto.gov.br/ccivil_03/leis/l7853.htm Acesso em 10 de Novembro de 2020.

BRASIL. Decreto № 10.502, de 30 de setembro de 2020. Institui a Política Nacional de Educação Especial: Equitativa, Inclusiva e com Aprendizado ao Longo da Vida. 2020. Disponível em: http://www.planalto.gov.br/ccivil_03/_ato20192022/2020/decreto/D10502.htm Acesso em 10 de Novembro de 2020.

BRASIL. Decreto № 3.956, de 8 de outubro de 2001. Promulga a Convenção Interamericana para a Eliminação de Todas as Formas de Discriminação contra as Pessoas Portadoras de Deficiência. Guatemala: 2001.

BRASIL. Estatuto da Criança e do Adolescente. Lei no 8.069, de 13 de julho de 1990. Disponível em: http://www.planalto.gov.br/ccivil_03/leis/l8069.htm Acesso em 1 de fevereiro de 2020.

BRASIL. Lei Brasileira de Inclusão. 2015. Disponível em: https://www12.senado.leg.br Acesso em 07 de Janeiro de 2019.

BRASIL. Manual de Orientação: Programa de Implantação de Sala de Recursos Multifuncionais. 2010. Disponível em: http://portal.mec.gov.br/index.php?9936-

RC: 84481

Disponível em: https://www.nucleodoconhecimento.com.br/educacao/inclusiva-confluencias 
manual-orientacao-programa-implantacao-salas-recursos-

multifuncionais\&ltemid=30192 Acesso em 27 de Janeiro de 2020

BRASIL. Plano Nacional de Educação 2014-2024. Brasília. 25 de junho de 2014.

\section{BRASIL. Política Nacional de Educação Especial na Perspectiva da Educação} Inclusiva. Brasília. Janeiro de 2008. Disponível em: http://portal.mec.gov.br/arquivos/pdf/politicaeducespecial.pdf Acesso em 27 de Janeiro de 2020.

BRASIL. Resolução CNE/CEB no 2 de 11 de setembro de 2001. Diretrizes Nacionais para a Educação Especial na Educação Básica. Disponível em: http://portal.mec.gov.br/cne/arquivos/pdf/CEB0201.pdf Acesso em: 19 de janeiro de 2020.

BRASIL. Resumo Técnico: Censo da Educação Básica. 2018. Disponível em: http://download.inep.gov.br/educacao_basica/censo_escolar/resumos_tecnicos/resu mo_tecnico_censo_educacao_basica_2018.pdf Acesso em 28 de Janeiro de 2020.

BRASIL. Lei de Diretrizes e Bases da Educação Nacional. Lei no 9394 de 20 de Dezembro de $1996 . \quad$ Disponível em: http://www.planalto.gov.br/ccivil_03/leis/L9394.htm Acesso em 20 de Dezembro de 2018.

FREIRE, Paulo. Pedagogia da Autonomia: Saberes Necessários à Prática Educativa. Editora: Paz\&Terra. Rio de Janeiro/ São Paulo - 43a edição. 2011.

FREIRE, Paulo. Pedagogia da Esperança: Um Reencontro com a Pedagogia do Oprimido. Editora: Paz\&Terra. São Paulo/Rio de Janeiro - 24ª edição. 2018.

FREIRE, Paulo. Pedagogia do oprimido. Editora: Paz e Terra - 38ª edição, 2004. 
GLAT, Rosana. BLANCO, Leila de Macedo Varela. Educação Especial no Contexto de uma Educação Inclusiva. In: GLAT, Rosana (Org e Ed.) Educação Inclusiva: Cultura e Cotidiano Escolar. Editora: 7Letras. 2013. P. 15-35.

GLAT, Rosana. Educação Inclusiva: Cultura e Cotidiano Escolar. 7Letras. 2007.

GLAT, Rosana. NOGUEIRA, Mario Lucio de Lima. Políticas Educacionais e a Formação de Professores para a Educação Inclusiva no Brasil. Caderno do Programa de Pós-Graduação em Educação. Comunicações. Ano 10, oㅜ 1, Junho de 2003.

GONÇALVES, TaísaGrasiela G. Liduenha. BUENO, José Geraldo Silveira. MELETTI, Silvia Márcia Ferreira. Matrículas de Alunos com Deficiência na EJA: Uma Análise dos Indicadores Educacionais Brasileiros. RBPAE, v.29, № 3, p. 407-426. 2013. Disponível em: https://www.seer.ufrgs.br/rbpae/article/viewFile/47212/29417 Acesso em 17 de março de 2019.

HENRIQUES, Cláudio Cezar. SIMÕES, Darcília (org). A Redação de Trabalhos Acadêmicos: Teoria e Prática. $7^{a}$ edição. Rio de Janeiro. Editora: EdUERJ. 2017.

JULIÃO, Elionaldo F. A diversidade dos sujeitos da EJA. In: MEDEIROS, Cecília. Educação de Jovens, Adultos e Idosos na Diversidade: saberes, sujeitos e práticas. Niterói, RJ, CEAD/UFF, 2015, p.157-170.

MOREIRA, Camila. O Direito de Educação para Jovens e Adultos com Deficiência. Espírito Santo. 2014. Disponível em: https://cmoreira2.jusbrasil.com.br/artigos ／113639657/o-direito-de-educacao-parajovens-e-adultos-com-deficiencia Acesso em 05 de Janeiro de 2019.

PAIVA, Jane. Histórico da EJA no Brasil: descontinuidades e políticas públicas insuficientes. Políticas de direito à educação: compromisso ético para consolidar o direito para todos os brasileiros. Salto para o Futuro - Livro: EJA: Formação Técnica 
e Integrada ao Ensino Médio. 2006P. 24 - 35. Disponível em: http://portal.mec.gov.br/setec/arquivos/pdf2/boletim_salto16.pdf\#page=24 Acesso em 10 de março de 2019

SCHUELER, Paulo. O que é uma Pandemia? Março de 2020. Disponível em: https://www.bio.fiocruz.br/index.php/br/noticias/1763-o-que-e-uma-pandemia Acesso em 10 de outubro de 2020.

SILVA, Ana Cláudia; LOPES, Giovana Cerqueira; LINO, Lucília Augusta. Investimento e qualidade da Educação de Jovens e Adultos. IN: ANFOPE, ANPAE. Anais do XI Encontro Regional SUDESTE da ANFOPE / XI Seminário Regional da ANPAE Sudeste /XIV Encontro Estadual da ANFOPE-RJ / VII Seminário Estadual da ANPAE-RJ. 'Política, gestão e formação de professores: (contra)reformas e resistências'. Niterói, UFF, 2018. Vol. 4, pp.22-26. ISBN: 978-85-922051-4-0. Disponível em: http://www.anfope.org.br/publicacoes/ Acesso em 10 de Setembro de 2020.

SOUZA, Kleyne Cristina Dornelas de. SILVA, Leda Regina Bitencourt da Silva. Educação Especial na Educação de Jovens e Adultos. Revista Com Censo. 2 ${ }^{a}$ Edição Especial, ำ5. 2016. ISSN 2359-2494. Disponível em: http://www.periodicos.se.df. gov.br/index.php/comcenso/article/view/74 Acesso em 06 de Janeiro de 2019.

TRENTIN, Valéria Becher. Educação de Jovens e Adultos e a Educação Especial nas Pesquisas: Uma Articulação Necessária. Revista Espacios. Vol. 38, ISSN 07981015. 2017.

UNESCO. Declaração de Salamanca e linha de ação sobre necessidades educativas especiais. Brasília: UNESCO, 1994. Disponível em: http://portal.mec.gov.br/seesp/arquivos/pdf/salamanca.pdf Acesso em 02 de Janeiro de 2019.

RC: 84481

Disponível em: https://www.nucleodoconhecimento.com.br/educacao/inclusiva-confluencias 
UNESCO. Declaração Mundial Sobre Educação Para Todos. Jomtien, Tailândia. 1990. Disponível em: www.unesdoc.unesco.org/images/0008/000862/086291por.pdf Acesso em 02 de janeiro de 2019.

VASCONCELOS, Maria Lucia; BRITO, Regina Helena Pires de. Conceitos de Educação em Paulo Freire. Editora: Vozes. São Paulo. 2019.

\section{APÊNDICE - REFERÊNCIA DE NOTA DE RODAPÉ}

3. Lei no $13.146 / 2015$, criada no dia 06 de julho de 2015 , entrando em vigor no dia 02 de janeiro de 2016.

4. Especialmente as Declarações originadas nas conferências de Jointiem (1990), sobre Educação Para Todos, e Salamanca (1994), sobre necessidades educativas especiais.

5. Refere-se ao confinamento e reclusão: "Esconder àqueles que ferem a normalidade instituída socialmente, tal qual às práticas desde a Idade Média até o século XX [...], no que se refere ao tratamento dado às pessoas com deficiência". (BASTOS, 2011, p.12)

6. No Rio de Janeiro, mais especificamente na Universidade do Estado do Rio de Janeiro (UERJ), a autora (TRENTIN, 2017), encontrou apenas uma das 19 pesquisas, realizadas, sendo que esta foi concluída em 2013.

7. Em 1988, a obrigatoriedade escolar ia apenas dos 7 aos 14 anos, mas a Emenda Constitucional 59/2009 acrescentou imediatamente um ano de escolaridade (Ensino fundamental de 9 anos, começando aos 6 anos de idade), e determinou que a partir de 2016, se estenderia dos 4 aos 17 anos de idade.

RC: 84481

Disponível em: https://www.nucleodoconhecimento.com.br/educacao/inclusiva-confluencias 
8. O AEE caracteriza-se por "identificar, elaborar e organiza recursos pedagógicos e de acessibilidade que eliminem as barreiras para a plena participação dos alunos, considerando as suas necessidades específicas. As atividades desenvolvidas [...] diferenciam-se daquelas realizadas na sala de aula comum, não sendo substitutivas à escolarização. Esse atendimento complementa e/ou suplementa a formação dos alunos com vistas à autonomia e independência na escola e fora dela" (BRASIL, 2008, p.16)

9. As CREs, em número de 11, abrangem as escolas de um grupo de bairros próximos. Ver Relação de Abrangência das Coordenadorias Regionais de Educação. Disponível em http://webapp.sme.rio.rj.gov.br/ jcartela/publico/ pesquisa.do?cmd=listCre Acesso em 28 Jan. 2020.

10. Ver Relação de Unidades Escolares com Salas de Recursos Multifuncionais. 2019. Disponível em: http://www.rio.rj.gov.br/web/sme/exibenoticias?id=6867261 Acesso em 28 Jan. 2020.

11. Para a sala de tipo I são disponibilizados equipamentos como: microcomputadores, laptop, estabilizador, scanner, impressora laser, teclado colméia, acionador de pressão, mouse com entrada para acionador, lupa eletrônica. E os seguintes mobiliários e materiais didáticos: mesa redonda, cadeiras, mesa para impressora armário, quadro branco, mesas para computador, material dourado, esquema corporal, bandinha rítmica, memória de numerais I, tapete alfabético encaixado, software comunicação alternativa, sacolão criativo, quebra cabeças de sequência lógica, dominó de associação de ideias, tátil, de frases, de animais e frutas em libras, alfabeto Braille, kit de lupas manuais, plano inclinado e memória tátil. (BRASIL, 2010, p.11)

12. Segundo o Manual (BRASIL, 2010), além dos utensílios presentes nasala Tipo 1, a sala de tipo II tem disponibilizado, no período estipulado no manual, os seguintes

RC: 84481

Disponível em: https://www.nucleodoconhecimento.com.br/educacao/inclusiva-confluencias 
equipamentos e materiais didáticos: impressora Braille, máquina de datilografia Braille, reglete de mesa, punção, soroban, guia de assinatura, kit de desenho geométrico e calculadora sonora.

13. Ver Unidades Escolares com Educação de Jovens e Adultos, Rio de Janeiro, 2019 e Relação de Unidades Escolares com Salas de Recursos Multifuncionais, Rio de Janeiro. 2019. Ambas disponíveis

em: http://www.rio.rj.gov.br/web/sme/exibenoticias?id=6867261 Acesso em 28 Jan. 2020.

14. Centro de Referência de Educação do Rio de Janeiro, localizado no centro do Rio.

15. A informação não é compatível com os dados disponibilizados.

16. A acomodação citada faz parte do processo de Adaptação de Jean Piaget, "que envolve a assimilação e a acomodação em uma relação indissociável, é o mecanismo que permite ao homem não só transformar os elementos assimilados, tornando-os parte da estrutura do organismo, como possibilitar o ajuste e a acomodação desse organismo aos elementos incorporados", ou seja, a acomodação de novos elementos e aprendizagens é modificar as estruturas para que se aprenda e incorpore o conhecimento o qual aprendeu. (BOCK; FURTADO; TEIXEIRA, 2008, p.139)

17. Schueler (2020) apresenta a doença Covid-19, causada pelo coronavírus, classificada como pandemia ao se disseminar rapidamente por todos os continentes, já causou a morte de mais de um milhão de pessoas, sendo mais de 180.000 no Brasil, teve impactos na economia, na cultura, na educação, alterando o modo de vida da população, ao impor o distanciamento social como modo de reduzir a contaminação.

18. Entre elas destacamos: ABRAÇA - Associação Brasileira para Ação por Direitos das Pessoas Autistas; ABRASCO - Associação Brasileira de Saúde Coletiva; ANPED - Associação Nacional de Pesquisa e Pós-Graduação em Educação; ANFOPE Associação Nacional pela Formação dos Profissionais da Educação; CNTE RC: 84481

Disponível em: https://www.nucleodoconhecimento.com.br/educacao/inclusiva-confluencias 
Confederação Nacional dos Trabalhadores em Educação; Campanha Nacional pelo Direito à Educação; Associação Brasileira de Psicopedagogia; FONEI- Fórum Nacional de Educação Inclusiva, que congrega dezenas de instituições, entre tantas outras manifestações.

19. Disponível em https://www.conjur.com.br/2020-dez-02/decreto-politica-educacaoespecial-suspenso-toffoli Acesso em 10 dez2020.

Enviado: Março de 2021.

Aprovado: Abril de 2021. 